\title{
Preservação do patrimônio arquitetônico: a educação patrimonial como possibilidade de manter viva e latente a história das cidades
}

\section{Preservation of architectural heritage: heritage education as a possibility to keep the history of cities alive and latent}

\author{
Tarcisio Dorn de Oliveira ${ }^{1 *}$, Helena Copetti Callai ${ }^{1}$, Luísa Pereira Zamin ${ }^{1}$, Matheus Mendonça \\ da Rocha ${ }^{1}$, Jéssica Patrícia Tolfo ${ }^{1}$
}

\begin{abstract}
RESUMO
A preservação patrimonial mostra-se extremamente relevante, ao passo que auxilia no entendimento e na compreensão da cultura e da memória das cidades, através da conservação de seus bens edificados. Por meio de uma pesquisa bibliográfica e documental, o texto intenta refletir sobre a preservação da arquitetura das cidades, tendo como meio a educação patrimonial, pois tal metodologia preservacionista apresenta-se fundamental na salvaguarda das memorias, das relações e das culturas das cidades. A preservação das cidades e da arquitetura que elas contem compõem experiências e significados as quais dão sentido ao mundo. Assim, a educação patrimonial baseia-se em um método ativo, com o intuito de ensinar a população a conhecer e a valorizar o seu patrimônio local, compartilhando, posteriormente, esses conhecimentos e saberes. Ao promover uma interação entre a história, a memória, a identidade e o pertencimento, a arquitetura proporciona ao indivíduo prazer e satisfação ao fazer a leitura do mundo em que está inserido.
\end{abstract}

Palavras-chave: Cidade; Arquitetura; Preservação; Educação Patrimonial;

\begin{abstract}
Heritage preservation is extremely relevant, while helping to understand and understand the culture and memory of cities, through the conservation of their built assets. Through a bibliographic and documentary research, the text intends to reflect on the preservation of the architecture of cities, having as a means of heritage education, as such preservationist methodology is fundamental in safeguarding the memories, relationships and cultures of cities. The preservation of cities and the architecture they contain compose experiences and meanings which give meaning to the world. Thus, heritage education is based on an active method, with the aim of teaching the population to know and value their local heritage, later sharing this knowledge and knowledge. By promoting an interaction between history, memory, identity and belonging, architecture provides individuals with pleasure and satisfaction when reading the world in which they live.
\end{abstract}

Keywords: City; Architecture; Preservation; Heritage Education;

${ }^{1}$ Universidade Regional do Noroeste do Estado do Rio Grande do Sul (UNIJUÍ).

*E-mail: tarcisio_dorn@hotmail.com 


\title{
INTRODUÇÃO
}

O patrimônio arquitetônico é parte das nossas histórias e registros das vidas vividas, diz, portanto, da tradição que carregamos junto com nós. E cidade é o lugar onde vivemos e construímos as nossas histórias. Está nela o registro das heranças que acolhemos e os nossos feitos na vida que estamos nela vivendo, e as culturas expressam essas duas dimensões que nas cidades estão demarcadas.

Assim, a cultura é definida por um conjunto de ações e tradições pelas quais civilizações, regiões e/ou povoados expressam-se, ao passo que, diferentes formas de expressão, adquirem características singulares no tempo e no espaço, ocasionando culturas únicas e ricas, que manifestam-se através da arte, musica, comidas, vestimentas e, de forma especial, na arquitetura.

No decorrer da história, determinadas culturas são modificadas, sobrepostas, agregadas a outras ou até mesmo perdidas, haja vista, que o desenvolvimento oriundo dos avanços contemporâneos passa a ocupar os antigos espaços - nesse processo, institui-se uma perda significativa da essência da memória desses lugares. Nesse entendimento é possível compreender que:

\begin{abstract}
Os bens patrimoniais atuam como suporte do imaginário e da memória social de uma localidade, ou seja, os edifícios e áreas urbanas possuidoras de valor patrimonial podem ser tomados como um ponto de apoio da construção da memória social, onde a educação nesse contexto, trata-se de um processo permanente e sistemático de trabalho centrado na arquitetura como fonte primária de conhecimento individual e ou coletivo (OLIVEIRA; CALLAI, 2017, p. 147).
\end{abstract}

Percebe-se, que a preservação patrimonial não apenas auxilia na manutenção e conservação dos ambientes, mas, acima de tudo, guarda a memória e a cultura dos povos, haja vista, que as memórias e costumes passados de geração em geração são manifestações patrimoniais encontradas na atualidade. Um bem de caráter patrimonial remete ao pertencimento e a identidade de uma geração ao lugar, pois tais ambiências trazem em sua essencialidade história e memória que dão força ao lugar. Nesse sentido pode-se observar que:

Proteger a arquitetura é manter vivas as marcas da história ao longo do tempo, assegurando a possibilidade de que as gerações futuras tomem conhecimento das manifestações materiais produzidas socialmente ao longo do tempo. $\mathrm{O}$ traçado da cidade, os desenhos dos passeios, as praças, o paisagismo, as manifestações culturais, os costumes, os saberes, as práticas culturais tornamse referências simbólicas e afetivas da sociedade em relação ao espaço vivido, e constituem a imagem e a identidade da cidade (OLIVEIRA; CALLAI, 2017, p. 147).

Isso, dá-se com a atribuição de valores e significados a bens patrimoniais, ainda remanescentes, de relevância cultural e arquitetônica que detêm a história de um povo e/ou de um 
lugar - nesse contexto, a educação patrimonial é uma possibilidade de manter a história das cidades, por meio de uma arquitetura viva, latente e provocativa. A educação patrimonial mostrase como um instrumento, pelo qual o indivíduo é capaz de compreender o mundo e o contexto social, cultural e histórico no qual está inserido. Para Horta, Grumberg e Monteiro (1999, p. 04):

[...] o contato direto com as evidências e manifestações da cultura, em todos os seus múltiplos aspectos, sentidos e significados, o trabalho de educação patrimonial busca levar as crianças e adultos a um processo ativo de conhecimento, apropriação e valorização de sua herança cultural, capacitandoos para um melhor usufruto destes bens, e propiciando a geração e a produção de novos conhecimentos, num processo contínuo de criação cultural.

O (re) conhecimento e, ao mesmo tempo, um olhar crítico por parte da população mostram-se fundamentais par uma efetiva preservação do patrimônio. Permitir a interação entre a comunidade e os espaços à serem conservados proporciona aos indivíduos o desenvolvimento de um sentimento de pertencimento à cidade o que, naturalmente, contribui para a salvaguarda dos espaços urbanos.

A preservação patrimonial mostra-se extremamente relevante, ao passo que auxilia no entendimento e na compreensão da cultura e da memória das cidades, através da conservação de seus bens edificados. Nesse entendimento, o texto intenta refletir sobre a preservação da arquitetura das cidades, tendo como meio a educação patrimonial, pois tal metodologia preservacionista apresenta-se fundamental na salvaguarda das memorias, das relações e das culturas das cidades.

A metodologia empregada, através dos procedimentos, estrutura-se por meio de uma pesquisa bibliográfica e documental, sendo que a pesquisa bibliográfica calca-se em teorias já publicadas propiciando que o pesquisador aproprie-se do conhecimento podendo sistematizar, analisar e (re) interpretar o material pesquisado, enquanto, a pesquisa documental apoia-se em fontes primárias (dados e informações) que precisam de um olhar científico e analítico.

\section{DESENVOLVIMENTO}

As manifestações culturais estão em constantes modificações, uma vez que, cada sujeito contribui com a inserção de novos costumes, conhecimentos e tradições no mundo da vida. A dinamicidade da vida reproduz e produz novos olhares assim como ações que se concretizam nos espaços da cidade, com expressões materializadas e outras imateriais e também intangíveis. Neste contexto o patrimônio arquitetônico assume todas essas dimensões e por isso é importante considerá-lo para manter viva e latente as histórias da cidade. 
Logo, para que o patrimônio arquitetônico seja preservado é necessário que a população possua conhecimento e pertença sobre o mesmo, de forma, a conseguir estabelecer significados e valores às edificações. Tais heranças deixadas pelos antepassados possuem significativa relevância cultural, histórica e morfológica ligando-se diretamente à memória, à identidade e ao pertencimento. Sobre o passado vinculando o patrimônio arquitetônico é oportuno observar que:

[...] revela um sentimento de identidade e pertencimento trazendo consciência da sociedade às pessoas através do tempo e espaço. A arquitetura do passado propicia estabilidade, haja visto, que o futuro é o destino incerto e o presente o instante fugaz. Assim, a única certeza que o ser humano possui é a verdade vivida e materializada no e do passado. Então, a preservação arquitetônica fazse em torno da relevância cultural e/ou morfológica, simbolizando o poder transmitido às pessoas do presente e do futuro, derivando da intenção de fazer do espaço urbano um espaço exuberante capaz de gerar emoções, reviver tradições e recapitular relações através do tempo entre o perto (presente) e o longe (passado) (OLIVEIRA; LOPES, 2018, p. 13-14).

Interessa, pois, neste sentido lembrar que o passado já foi, passou e o futuro ninguém sabe o que será. O momento presente é o único que temos na vida para fazer algo, sempre considerando o que o passado nos legou com as marcas que deixou e, do mesmo modo criando condições para viver a vida atualmente, que deixará as marcas e condições para o futuro, seja ele qual for.

O passado pode nos alimentar pela tradição e diante disso é fundamental conhecer e reconhecer os bens arquitetônicos que são relevantes para resgatar a história, a memória, a identidade e os acontecimentos passados, podendo compreender o universo social e cultural, bem como, sua trajetória histórica e temporal em que estão inseridos. Ao preservá-los espera-se que o indivíduo faça a leitura do espaço que o rodeia, (re) montando e contando a história do passado. Nesse sentido:

O território em que vivemos é mais que um simples conjunto de objetos, mediante os quais trabalhamos, circulamos, moramos, mas também um dado simbólico. A linguagem regional faz parte desse mundo de símbolos, e ajuda a criar essa amálgama, sem o qual não se pode falar de territorialidade. Esta não provém do simples fato de viver num lugar, mas da comunhão que com ele mantemos (MARTINS, 2006, p. 39).

A territorialidade diz do chão em que vivemos e ela tem as marcas materiais que são visíveis mas também e essencialmente as marcas simbólicas que pela linguagem, pelos sentimentos e pela cultura se manifestam. E as cidades ocupam e constituem territórios que tem memória, tem vida e possibilidades para o futuro.

A preservação das cidades e da arquitetura que elas contem compõem experiências e significados as quais dão sentido ao mundo. Esses bens oferecem aos sujeitos subsídios para a construção do conhecimento e da valorização dos espaços urbanizados, possibilitando a noção de despertar sentimentos de pertencimento e afetividade aos sujeitos ao lugar em que vivem. 
A necessidade de compreender os bens patrimoniais remanescentes vem a agregar conhecimento a todos e fomentar a proteção dos mesmos, haja vista, que a educação patrimonial mostra-se como uma metodologia de permitir que tanto crianças, jovens e adultos tenham acesso ao conhecimento, com o objetivo de enriquecer os indivíduos através da cultura e da história, proporcionando um olhar crítico sobre o mundo contemporâneo e sobre a sociedade atual.

\begin{abstract}
A arquitetura possui a capacidade de estimular a memória das pessoas, e por isso, é alvo de estratégias que visam a sua promoção e preservação, onde a preocupação em protegê-lo começou no início do século XX, sendo criadas a partir daí várias normativas, comissões e conferências para estabelecer critérios para proteger e conservar o patrimônio. Observa-se a importância de entrelaçar situações de ensino e aprendizagem com o que se denomina de preservação da arquitetura, onde a noção de preservação do patrimônio surge junto a movimentos sociais que buscam a autonomia e a valorização da cultura local e global (OLIVEIRA; CALLAI, 2017, p. 147).
\end{abstract}

O fato é que a cidade é composta pelos cidadãos e que estes mostram-se presentes e atuantes na cultura e proteção da história local desvelando a compreensão sobre o patrimônio, haja vista, que as atividades e fenômenos que englobam a população local contribuem de forma positiva no entrosamento dos cidadãos com a forma e constituição de sua cidade.

Constituem-se uma parcela significativa do patrimônio as edificações remanescentes que fazem parte da história da cidade, os quais são (re) conhecidos por sua construção representativa e/ou por seu estilo e/ou por sua técnica construtiva e/ou sua época de construção. Tais patrimônios são constituídos por bens que referem-se à identidade e à memória urbana coletiva que compõem os espaços urbanos. Nesse sentido a arquitetura vista como monumento:

[...] não se limita somente à edificação (objeto), uma vez que ela denota uma carga simbólica e abstrata, ou seja, a sua monumentalidade, a qual tem por função trabalhar sobre o imaginário social. A arquitetura possui em si uma monumentalidade, a qual transcende, refletida na ambiência urbana por uma ideia, concepção e crença, haja visto, que os bens patrimoniais (objetossímbolo) propiciam às pessoas a possibilidade de viajar no imaginário. Dessa forma, a força desses monumentos são ideias e imagens transpostas ao espaço e, num caminho inverso, espaço transposto às ideias e às imagens como fruto e semente do imaginário. Assim, está na arquitetura patrimonial a força do monumento e da monumentalidade, estando nos lugares e no imaginário da humanidade (OLIVEIRA; LOPES, 2018, p. 14).

A ligação entre educação patrimonial e a preservação do patrimônio é fundamental para a formação da sociedade, pois a metodologia educacional centrada na arquitetura é uma ferramenta primordial de gestão e formação cultural. Para Callai (2005, p. 232) "partindo do fato de que a gente lê o mundo ainda muito antes de ler a palavra, a principal questão é exercitar a prática de fazer a leitura do mundo. Assim, a educação patrimonial fomenta nos sujeitos habilidades para a leitura do mundo que os rodeia e para a compreensão do universo sociocultural em que estão inseridos. 
Horta, Grumberg e Monteiro (1999, p. 06) entendem que a educação patrimonial está relacionada "em provocar situações de aprendizado sobre o processo cultural e suas manifestações, que despertem nos alunos o interesse em resolver questões significativas para sua própria vida, pessoal e coletiva". Assim, a educação patrimonial, tem um forte papel social ao passo que:

[...] várias interpretações, tornando-se um instrumento importante de promoção e vivência da cidadania, podendo defini-la, como um ensino centrado nos bens culturais, onde a metodologia toma estes bens como ponto de partida para desenvolver tarefas pedagógicas que consideram tais bens como fonte primária do ensino consequentemente gerando a responsabilidade na busca, na valorização e na preservação, onde o processo educativo tem como objetivo levar os sujeitos a utilizarem suas capacidades intelectuais para a aquisição e o uso de conceitos e habilidades, na prática, em sua vida diária e no próprio processo educacional (OLIVEIRA; CALLAI, 2017, p. 148).

A educação patrimonial é um método de trabalho percebido e atingido como uma metodologia de instrução e formação cidadã e cultural, a qual, possui como premissas instigar os sujeitos a compreenderem os aspectos sociais e culturais de sua cidade resgatando a relação de afeto pelo patrimônio. Esse encadeamento possibilita criar um processo de conhecimento, apropriação e valorização das heranças culturais capacitando os sujeitos para melhor usufruir esses bens. Nesse viés, trabalhar a educação e a arquitetura deve estabelecer:

[...] um diálogo interdisciplinar em que diversos saberes serão envolvidos. [...] é preciso levar em consideração a cultura local com todos os seus saberes, sabores, vestígios do passado e espaços de memória em que é preciso reconhecer, pois são trilhas iniciais necessárias para um processo educacional para o grupo com o qual quer se envolver e com quem se estará em contato. Também é preciso se ter consciência que para transitar pela educação patrimonial é necessário manter diálogos com diferentes ciências como a educação, história e antropologia, saberes esses que vem se debruçando com mais sensibilidade ao campo do patrimônio. O diálogo permanente que está implícito neste processo educacional estimula e facilita a comunicação e a interação entre as comunidades e os agentes responsáveis pela preservação e estudo dos bens culturais, possibilitando a troca de conhecimentos e a formação de parcerias para a proteção e valorização desses bens (APOLINÁRIO, 2012, p. 60-61).

Para manter uma cultura viva surge a necessidade de preservar o que resta dela, pois os patrimônios arquitetônicos contem em si possibilidades múltiplas para trabalhar a história, a memória e a identidade com os valores culturais locais. Para isso, torna-se fundante utilizar tais bens como recursos educacionais, trabalhando de forma a levar aos sujeitos experiências que contemplem a percepção e a motivação pela salvaguarda do ambiente construído.

Segundo Horta, Grunberg e Monteiro (1999) a educação patrimonial leva os indivíduos a um processo ativo de conhecimento, de apropriação e de valorização da herança cultural, além de possibilitar o melhor usufruto destes bens e proporcionar a produção de novos conhecimentos, 
em um processo contínuo de criação cultural, permitindo assim, fortalecer os sentimentos de identidade e cidadania. Ainda é pertinente salientar que a educação patrimonial pode ser compreendida:

[...] como uma estratégia pedagógica para ampliar parcerias e buscar soluções de forma democrática, principalmente promovendo uma aproximação direta entre escolas e as casas do patrimônio, apoiadas ou implementadas pelo Iphan, existentes em diversos territórios brasileiros. O trabalho com educação patrimonial contribui no processo educativo, tendo como foco o patrimônio cultural como recurso para compreensão das referências culturais em todas as suas manifestações, com objetivo de contribuir para o reconhecimento, valorização e preservação do patrimônio cultural local, regional e nacional (LIMA, 2012, p. 53-54).

A educação patrimonial centrada na arquitetura dá-se como uma forma de conscientizar os sujeitos do quão importante é preservar os bens culturais, para que não haja a perda da identidade local por mudanças e interferências do mundo globalizado. Complementando, Horta, Grunberg e Monteiro (2009, p.5), trazem que "neste processo dinâmico de sociabilização em que se aprende a fazer parte de um grupo social, o indivíduo constrói a própria identidade". Logo admitir e aceitar que os sujeitos criam e constituem cultura, cada um de forma diferenciada, é fundamental para concordar e consentir a diversidade cultural. Nessa perspectiva:

[...] cabe à educação patrimonial proceder à escuta e à mediação dos sujeitos sociais portadores de tradições, de saberes e fazeres que, em sua diversidade, constroem atrativos geradores de significação e integradores da identidade e identificação cultural. É sua responsabilidade sensibilizar e conscientiza as comunidades em torno de seus valores e tradições, inserindo tais práticas na vida sustentável, resgatando e preservando o imaginário coletivo e o patrimônio representativo da cultura, no eixo temporal e espacial (FARIAS, 2002, p. 62).

A educação patrimonial baseia-se em um método ativo, com o intuito de ensinar a população a conhecer e a valorizar o seu patrimônio local, compartilhando, posteriormente, esses conhecimentos e saberes. Ao promover uma interação entre a história, a memória, a identidade e o pertencimento, a arquitetura proporciona ao indivíduo prazer e satisfação ao fazer a leitura do mundo em que está inserido.

A arquitetura, vista como bem patrimonial, é valiosa o que justifica sua permanência e preservação, pois, em parte, são nelas que estão inseridas as lembranças de quem as deixa. Tais bens registram identidades de seus antepassados armazenando histórias e criando memória de uma população e formando seu próprio futuro a partir de seus referenciais culturais. Permitindo não apenas a conservação da história e da memória, mas também, instigando a construção de um futuro baseado em um olhar crítico e em uma valorização da identidade social local, criando novos conhecimentos em processo continuo de construção social. 


\section{CONSIDERAÇÕES FINAIS}

Estudar e compreender a importância da preservação do patrimônio abrange mais do que meramente o conhecimento sobre o tema, abarca um entendimento maior sobre a cultura, memória e identidade constituintes das ambiências urbanas e da vida dos sujeitos, pois propicia uma história sólida, sem lapsos criados com o desmantelamento da arquitetura e da cidade. Notase hoje, um período de pouca ou quase nenhuma valorização patrimonial, o que acarreta na destruição de bens significativos, apagando as memórias vinculadas a eles.

O conhecimento sobre o patrimônio não deve ficar apenas entre os teóricos e profissionais da área, pelo contrário, deve ser semeado a todos, para que assim seja possível estabelecer situações preservacionistas para a cidade e seus bens patrimoniais. As crianças são o futuro, e do pensamento delas, nascem inúmeras coisas boas; a educação sempre vai ser a chave para um mundo melhor, com a educação patrimonial será possível levar conhecimento a mais pessoas para que todos possam envolver-se com êxito na proteção.

Os processos educativos das nossas crianças, tendo essa perspectiva aqui enunciada, prepara-as para conhecer e pensar sobre a própria vida, para compreenderem que alguém antes delas já viveu e produziu os bens materiais e imateriais que agora ela tem acesso. E com este olhar de respeito e preservação as crianças podem dizer o que consideram que seria adequado para viver as vidas nas cidades. Não se trata apenas de preparar as crianças para o futuro, mas de ensina-las a ter o seu lugar como cidadãs no hoje aqui e agora das cidades em que vivem.

Sem dúvida um dos meios mais fundamentais para a efetiva preservação do patrimônio arquitetônico, é a utilização dos espaços, pois é através do uso que se mantem vivas as memorias e relações entre as pessoas e os ambientes, dentro desta conjuntura se mostra também muito relevante o conhecimento prévio destes locais, a história e a relevância dos mesmos para a formação tanto das cidades e regiões quanto para a formação social dos indivíduos.

No momento em que tem-se uma preocupação desde cedo com a proteção e preservação patrimonial, o cenário muda. O conhecimento prévio sobre o patrimônio permite a apropriação destes espaços, tornando possível a sua efetiva preservação. Desta forma a educação patrimonial faz parte de um leque amplo de alternativas que permitem não somente a preservação do patrimônio em si, mas também das culturas e tradições que fazem parte de um determinado grupo ou região.

A educação patrimonial apresenta-se intrínseca a preservação patrimonial arquitetônica, pois permitir que a sociedade conheça e aprenda sobre os espaços que os rodeiam, permitindo apropriar-se dos mesmos e naturalmente proporciona o sentimento de pertencimento. A educação patrimonial mostra-se imprescindível no âmbito da preservação patrimonial, tendo em vista que a mesma torna-se fundamental para o entendimento mais amplo da cultura, memória e do patrimônio a ser preservado. 


\section{REFERÊNCIAS}

APOLINÁRIO, J. R. Reflexões sobre a educação patrimonial e experiências da diversidade cultural no ensino de História. In: TOLENTINO, Á. B. (org.). Educação patrimonial: reflexões e práticas. João Pessoa: Superintendência do Iphan na Paraíba, 2012. 104 p. (Caderno temático, 2).

CALLAI, H. C. Aprendendo a ler o mundo: a geografia nos anos iniciais do Ensino Fundamental. Caderno Cedes, Campinas, SP, v. 25, n. 66, p. 227-247, maio 2005.

FARIAS, E. K. V. A construção de atrativos turísticos com a comunidade. In: MURTA, S. M.; ALBANO, C. (org.). Interpretar o patrimônio: um exercício do olhar. Belo Horizonte: Ed. UFMG; Território Brasilis, 2002.

HORTA, M. de L. P; GRUNBERG, E; MONTEIRO, A. Q. Guia básico de educação patrimonial. Brasília: Instituto do Patrimônio Histórico e Artístico Nacional; Museu Imperial, 1999.

LIMA, S. B. de M. Educação patrimonial é mais educação! In: TOLENTINO, Á. B. (org.). Educação patrimonial: reflexões e práticas. João Pessoa: Superintendência do Iphan na Paraíba, 2012. 104 p. (Caderno temático, 2).

MARTINS, C. Patrimônio cultural: da memória ao sentido do lugar. São Paulo: Roca, 2006.

OLIVEIRA, T. D. de; LOPES, C. E. J. Monumento, monumentalidade, valor e poder: interações com a memória e preservação arquitetônica. METAgraphias: letra JK de JK de utopias políticas possíveis, v. 3, n. 3, p. 1-17, 2018.

OLIVEIRA, T. D. de; CALLAI, H. C. Compreender a cidade e a arquitetura através da educação patrimonial. Revista Di@logus, Cruz Alta, RS, v. 6, n. 3, p. 141-149, set. 2017. 